Transport

Volume 171 Issue TR1

Routes for exceptional loads: a new soil mechanics perspective

Krechowiecki-Shaw, Royal, Jefferson and

Ghataora
Proceedings of the Institution of Civil Engineers

Transport 171 February 2018 Issue TR1

Pages 42-58 https://doi.org/10.1680/jtran.16.00109

Paper 1600109

Received 06/07/2016

Published online 09/05/2017

Accepted 09/02/2017

Keywords: foundations/pavement design/roads \& highways i

\title{
Routes for exceptional loads: a new soil mechanics perspective
}

\section{Christopher J. Krechowiecki-Shaw MEng}

Postgraduate Researcher, School of Civil Engineering,

University of Birmingham, Edgbaston, Birmingham, UK (corresponding author: CJS518@bham.ac.uk)

Alexander C. Royal MEng, PhD

Lecturer, School of Civil Engineering, University of Birmingham, Edgbaston, Birmingham, UK
Ian Jefferson BEng(Hons), DIS, PhD, FGS

Professor, School of Civil Engineering, University of Birmingham, Edgbaston, Birmingham, UK

Gurmel S. Ghataora BEng, PhD, MIMM, MILT

Senior Lecturer, School of Civil Engineering, University of Birmingham,

Edgbaston, Birmingham, UK

Off-site prefabrication can bring cost, quality and programme benefits to construction projects but often requires the transportation of large, indivisible loads (in the order of 1000-10 000 t) on temporary routes that can cross soft soils. Through simple numerical modelling, this paper demonstrates that the fundamental behaviour of the ground supporting these large loads can differ significantly from that expected in conventional road design practice; the interaction between many closely spaced wheels means the vehicle's influence depth and failure mechanism are significantly deeper. Surface soils are less influential. Deeper soil was found to be more prone to local yield, developing large localised strains at low proportions (10-30\%) of the ultimate capacity. Instead of designing temporary roads to avoid yield and degradation under cyclic loads, significant savings may be possible if limited degradation is permitted, with recovery through consolidation between loads. Investigation and monitoring of deep subsoils during operations is recommended for real-time evaluation of geotechnical risk.

\section{Notation}

$B \quad$ loaded width (m)

D pavement depth (m)

E Young's modulus (MPa)

$E_{0} \quad$ Young's modulus at top of layer (MPa)

$K_{0} \quad$ coefficient of lateral earth pressure at rest (dimensionless)

$K_{0, \mathrm{NC}} \quad$ normally consolidated coefficient of lateral earth pressure at rest (dimensionless)

$K_{0, \mathrm{OC}} \quad$ overconsolidated coefficient of lateral earth pressure at rest (dimensionless)

$m_{1} \quad$ increase in Young's modulus with depth (MPa/m)

$N_{\text {Su }} \quad$ shear strength ratio of clay subgrade,

$S_{\mathrm{u}} / \gamma_{\mathrm{p}}^{\prime} D$ (dimensionless)

$p^{\prime} \quad$ mean normal effective stress $(\mathrm{kPa})$

$q \quad$ deviator stress $(\mathrm{kPa})$

$S_{\mathrm{u}} \quad$ undrained shear strength $(\mathrm{kPa})$

$s_{\mathrm{E}} \quad$ settlement in linear-elastic model (m)

$s_{\mathrm{P}} \quad$ settlement in Mohr-Coulomb model (m)

$x$

$z_{\mathrm{NC}}$

lateral distance from vehicle or wheel centreline (m) depth to normal consolidation (m) total unit weight of pavement fill $\left(\mathrm{kN} / \mathrm{m}^{3}\right)$ effective unit weight of pavement fill $\left(\mathrm{kN} / \mathrm{m}^{3}\right)$ unit weight of subgrade $\left(\mathrm{kN} / \mathrm{m}^{3}\right)$ increment in vertical effective stress from wheel load $(\mathrm{kPa})$

utilisation of ultimate capacity (i.e. ratio of applied load to failure load, $\omega / \omega_{\text {ult }}$ ) (dimensionless)

Poisson's ratio (dimensionless) vertical effective stress $(\mathrm{kPa})$

angle of internal shearing resistance (degrees) uniformly distributed wheel load stress on pavement $(\mathrm{kPa})$ $\omega_{\text {ult }}$

ultimate $\omega$ at failure applied on a single wheel (or for each separate wheel in the case of multi-wheel models) in Mohr-Coulomb model (kPa)

\section{Introduction}

Demand for off-site prefabrication in the construction, mining and oil and gas industries (see Cronin, 2015; Mammoet, 2017) can necessitate the transportation of large indivisible loads to remote locations on temporary roads. These loads may be of the order of 1000-10000 t, transported by large, multiwheeled mobile platforms (e.g. $6 \mathrm{~m}$ wide by $60 \mathrm{~m}$ long, supported on 88 wheels). Economic limitations due to the road's short design life, coupled with logistical constraints, may preclude the use of ground improvement where soft soils are crossed, and the risk of cyclic degradation must be managed in such extreme conditions. Subgrade soil behaviour under these unconventional conditions is poorly understood and requires novel research for efficient road design.

Conventional pavements are designed to allow only a small amount of local yielding under each passage, otherwise cumulative strains render the pavement unserviceable. Unbound temporary roads need not be so robust (i.e. cumulative strains could be tolerated), but they must avoid deep-seated slip failure. This can form under repeated loads as localised yielding in the subgrade spreads. Understanding local yielding behaviour of heavy-haul road subgrade soil is fundamental for successful design. In the work reported here, a parametric finite-element analysis study was conducted to investigate how it varies with

- vehicle dimensions

- the proportion of capacity mobilised 
differences in pavement-subgrade system properties

- assumptions made in modelling soil behaviour.

Simple analysis methods are purposefully used to allow yielding behaviour to be isolated and examined. It is demonstrated that the practice of minimising local yield, when applied to large vehicles, can be prohibitively expensive for temporary assets; a procedure that instead monitors real-time degradation may yield cost benefits. Implications for site investigation and monitoring of heavy-haul roads are also discussed.

\section{Literature review}

\subsection{Transmission of loads through pavements}

\subsubsection{Domain of conventional road research}

Conventional pavement design aims to maintain low subgrade stress, well below its shear strength, by spreading wheel loads through an engineered fill layer (Brown, 1996; Frost et al., 2004). The resulting small strains are almost entirely recoverable, and irrecoverable strain is only measurable after multiple cycles (Brown, 1996). Within this small-strain regime (i.e. $<0.5 \%$ strain), elastic behaviour and constant post-cyclic shear strength can be assumed with acceptable accuracy (DíazRodriguez and López-Molina, 2008; Wang et al., 2014). Tannant and Regensburg (2001) presented a resilient-modulus design method that prescribes mine-road fill depths specifically to limit strains to this regime (1500 to 2000 microstrain). Subjecting subgrades to larger strains causes irrecoverable strain and degradation of shear strength (Brown et al., 1977; Wang et al., 2014).

Conventional pavement design is typically based on the response to the passage of a single wheel (Boulbibane et al., 2005; Brown, 1996; Sharp and Booker, 1984), as wheels on conventional vehicles are considered to be sufficiently separated to avoid interaction between wheel pressure bulbs. Individual pressure bulbs from closely spaced wheels can interact to form wider, deeper pressure bulbs (as encountered by Gräbe and Clayton (2009) when investigating deformation in railway foundations, where sleepers are more closely spaced than conventional road wheel loads). The interaction between closely spaced wheel loads (or railway sleepers) also potentially changes the failure mechanism from being localised under a wheel to acting over the whole vehicle (Lehtonen et al., 2015). This interaction and the deeper stressed zone must be considered in heavy-haul road design.

Conventional pavement design generally presumes that the upper subgrade layers are the most influential on the development of progressive failure (Brown, 1996; Little, 1992). Even heavily loaded mine- and forestry-haul roads use this approach; pavement design thickness is often based on either the California bearing ratio (CBR) or the resilient modulus of the subgrade surface (FCE, 2011; Kaufman and Ault, 1977; Tannant and Regensburg, 2001). For interacting multi-wheeled vehicles, the dominance of the upper, most overconsolidated layers will diminish and deeper, normally consolidated, saturated soils will become increasingly influential.

\subsubsection{Composite fill-subgrade system behaviour}

A pavement is often described as a 'composite system' (Brown, 1996; Frost, 2000; Hyde, 1974); strains are considered compatible at the interface and the stress distribution is influenced by the ratio of the pavement stiffness to the subgrade stiffness (relative stiffness). The role of engineered fill is primarily to spread the wheel load to keep subgrade stresses sufficiently low (Frost et al., 2004). Load on the subgrade is more efficiently distributed if the pavement relative stiffness increases, but above an optimum relative stiffness the pavement shears locally, reducing the composite capacity (Sharp and Booker, 1984).

Deeper pavements spread loads on the subgrade more widely, but the load-spreading angle decreases until a limiting depth is reached where behaviour is completely controlled by the pavement (Boulbibane et al., 2005; Burd and Frydman, 1997; Houlsby and Burd, 1999; Sharp and Booker, 1984). This effect has also been observed in scaled foundation tests (Ismail Ibrahim, 2016; Laman et al., 2012).

\subsubsection{Influence of principal stress rotation}

A moving wheel load continuously rotates the principal stresses (Brown, 1996). Cyclic principal stress rotation softens soil, causing significantly larger cumulative strains (Arthur et al., 1980; Jefferies et al., 2015; Xiao et al., 2014). Cyclic principal stress rotation has been found to result in accelerated failure (Gräbe and Clayton, 2009) when compared with a cyclic load that does not move (Brown and Chan, 1996).

Self-weight stresses are low beneath a conventional road (Brown, 1996); therefore, lateral stresses arising in front of (and behind) a moving wheel will cause large rotation of the principal stresses. Overlapping adjacent stress bulbs will to some extent 'cancel out' the lateral stress pulse between adjacent axles, causing these lateral stresses to occur at greater depths where principal stress rotation from a given lateral stress increment is reduced as a result of the increased selfweight stress. It is possible for two 'regimes' to exist - a shallow zone where principal stresses are rotated significantly by the passage of traffic and a deeper one where stress rotation is small. This is a complex stress-strain environment: the shallower overconsolidated zone experiences rapidly changing stresses (both magnitudes and principal directions) while the deeper zone, more prone to compressive yield, experiences smaller stress changes but is still likely to degrade quickly.

\subsection{Progressive failure and shakedown}

A stable equilibrium ('shakedown'), whereby only recoverable strain occurs under load, is reached if the pavement-subgrade 
system can effectively become 'prestressed' by a residual stress field to remain within elastic limits both under load and at rest (Ponter et al., 1985; Sharp and Booker, 1984; Zhao et al., 2008). Residual stresses are assumed to be mobilised through limited local yield during initial load passages. This suggests an additional reserve of resistance to repeated load slightly above the load that causes first local yield, but significantly below the static load causing collapse (Pande, 1982; Sharp and Booker, 1984). Constant strength and stiffness parameters are typically assumed (Boulbibane et al., 2005; Sharp and Booker, 1984; Zhao et al., 2008), characteristic of small- to mediumstrain soil behaviour (Díaz-Rodriguez and López-Molina, 2008), to model mathematically a limiting safe load or 'shakedown limit'. It should be noted that the shakedown limit differs from the cyclic threshold stress observed experimentally (e.g. Heath et al., 1972) - the former considers the whole pavement-subgrade system theoretically whereas the latter indicates loss of strength of a single soil element once sufficiently large strains occur (e.g. Wang et al., 2014). Full-scale pavement tests (Sharp and Booker, 1984) and scaled laboratory experiments on a range of soils (Juspi, 2007) have been found to compare well with theoretical shakedown limits. This suggests that residual stresses are the dominant factor in achieving equilibrium, and material strengths only degrade for loads above the shakedown limit. In particular, overconsolidated surface soils are predominantly elastic when loaded well below their shear strength (Brown, 1996; Schofield and Wroth, 1968) and the conventional approach of limiting subgrade surface strains is clearly valid for roads resisting predominantly small, separate wheel loads.

If the residual stress field required to counteract heavier loads cannot be achieved without yielding at rest, strain accumulates with each load application and the road fails progressively, typically accompanied by rising subgrade pore water pressures that reduce the strength (e.g. Frost, 2000; Gräbe and Clayton, 2009). Avoiding such degradation by limiting strains for large multi-wheeled vehicles crossing soft ground, where stresses extend to great depth, is likely to require a much thicker pavement layer. Such an approach would likely be unjustifiably costly and impractical for a temporary road. A better understanding of strength degradation from load and recovery from consolidation in medium/large-strain regimes, as discussed by Krechowiecki-Shaw et al. (2016), could achieve a more economic and practical design.

\subsection{Local yield}

As a surface load increases from zero towards the failure load, the first local yield is reached and plastic deformation occurs at a single point. A further increase in load causes more widespread yielding, redistributing stresses until the shear strength is mobilised over the full slip circle at failure (Madabhushi and Haigh, 2015; Osman and Boulton, 2005). In studying local yield, it is convenient to consider utilisation (i.e. the proportion of capacity mobilised, $\Lambda$ ), given by

$$
\text { 1. } \Lambda=\omega / \omega_{\text {ult }}
$$

Elastic-plastic finite-element modelling and corroborating field tests carried out by D'Appolonia et al. (1971) indicate that the first local yield depends heavily on the in situ stress state and shear strength. Both of these are determined by overconsolidation, which can be quantified by $N_{\mathrm{Su}}$ (see Equation 2, after Burd and Frydman (1997)). For normally consolidated soil, this may occur at $\Lambda=12-25 \%$, while local yield in heavily overconsolidated surface soils may only occur for $\Lambda>50 \%$ (D’Appolonia et al., 1971). Berardi and Lancellotta (2002) made similar observations related to oil tank settlements.

\section{2. $N_{\mathrm{Su}}=S_{\mathrm{u}} / \gamma_{\mathrm{p}}^{\prime} D$}

Burd and Frydman (1997) also found that $N_{\text {Su }}$ influences the failure mechanism: normally consolidated subgrades mobilised yield over larger volumes of soil, particularly developing yield in the compression zone directly beneath the load.

At rest, a normally consolidated soil has a lower value of $K_{0}$ (coefficient of lateral earth pressure at rest) and thus requires a smaller deviator stress increment to reach compressive yield. While compressive yield in deep normally consolidated soil is not a common problem for conventional roads, below a heavyhaul road it is a concern and was therefore investigated in this study. This paper focuses on the development of local yielding in soft soil at depth below unbound heavy-haul roads, rather than attempting accurate stress or settlement predictions. A number of simplifying assumptions were made in the finiteelement analyses to allow a 'first-approximation' of the problem to be developed.

\section{Analysis method}

\subsection{Modelling philosophy}

Simple linear-elastic and linear-elastic, perfectly plastic ('Mohr-Coulomb') models were used for the soil layers. While being unrealistic descriptors of element-level behaviour, over a soil mass these models can

- offer good agreement with yield development and failure mechanisms of site trials (D’Appolonia et al., 1971; Ismail Ibrahim, 2016), and

- allow the study of local yielding effects in isolation (D’Appolonia et al., 1971).

Single wheel loads were compared with multi-wheeled vehicles to identify changes in behaviour dependent on the interaction between wheels. The vehicle considered is long relative to its width and the wheels are closely spaced in the longitudinal direction (Figure 1). The three-dimensional layout was thus 
Routes for exceptional loads: a new soil

mechanics perspective

Krechowiecki-Shaw, Royal, Jefferson and

Ghataora

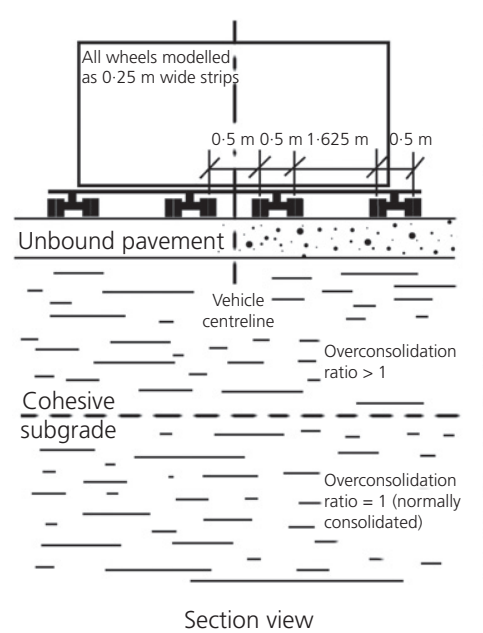

(a)
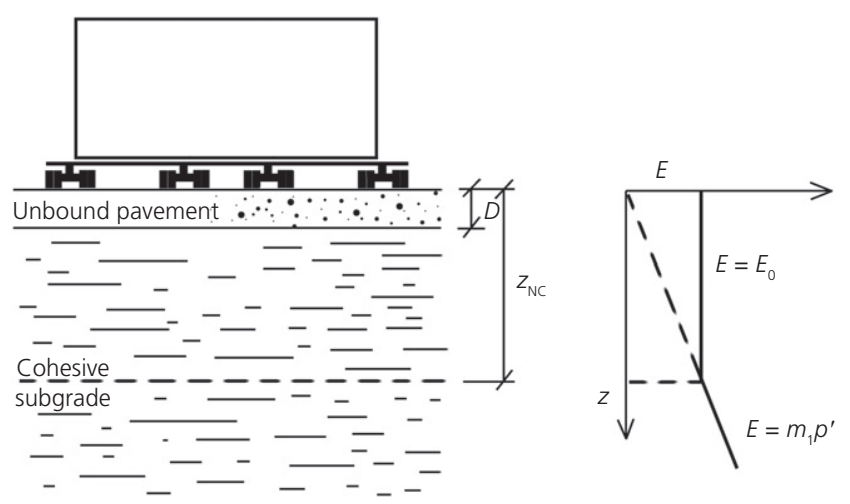

(b)

Figure 1. Problem definition: (a) vehicle geometry; (b) ground model for analysis. As a plane-strain analysis was used, the model geometry was based solely on the section view; the plan view is for information only

simplified to a two-dimensional, plane-strain analysis based on the section view. While a single wheel is more accurately represented by an axisymmetric (circular) load, conventional haulage vehicles often have multiple axles with small longitudinal spacing; some longitudinal interaction is likely to occur, making the response more similar to a strip load, hence single wheel loads are also simplified to a plane-strain strip load. Sharp and Booker (1984), Boulbibane et al. (2005) and Juspi (2007) similarly analysed moving single wheel loads as planestrain strips.

A range of subgrade models was simulated to represent normally consolidated to lightly overconsolidated, soft to very soft deposits with a high water table (i.e. areas with low bearing capacity likely to present difficulties to temporary roads, such as alluvial deltas). Soil parameters were chosen to reflect a low-plasticity (plasticity index, $\mathrm{PI}=10-15 \%$ ) silty to very silty clay. Overconsolidation was represented using the simplified model presented by Foye et al. (2008) in which the overconsolidated layer is modelled with a constant stiffness and shear strength, while deeper normally consolidated soil increases in stiffness and strength with depth (Figure 1). The properties of the pavement layer were also varied to investigate its influence on single and multiple wheel loads.

While principal stress rotation is known to influence the soil stress-strain response (Jefferies et al., 2015), such effects were not modelled in this work for the sake of simplicity and due to difficulties in obtaining realistic parameters. However, general trends in stress rotation were considered, as these can have a large influence on the subgrade degradation environment. The finite-element software Midas GTS NX (Midas, 2016) was used for all finite-element analyses.

\subsection{Soil models}

\subsubsection{Linear-elastic models}

Three separate linear-elastic clay subgrade models (representing varying degrees of overconsolidation) and a single granular pavement model, with properties as given in Table 1, were analysed. Below the depth to normal consolidation, $z_{\mathrm{NC}}$ (Figure 1(b)), the subgrade soil is assumed to be normally consolidated and hence Young's modulus is described by

\section{3. $E=m_{1} p^{\prime}$}

The case 1 subgrade model is such that $z_{\mathrm{NC}}$ coincides with the top of subgrade, to provide a theoretical minimum strength and stiffness.

The clay subgrade $K_{0}$ is assumed to take the normally consolidated value, following Brooker and Ireland (1965) (Equation 4). The granular pavement follows the work of Jaky (1948) (Equation 5).

\section{4. $K_{0, \mathrm{NC}}=0 \cdot 95-\sin \phi^{\prime}$}

\section{5. $K_{0, \mathrm{NC}}=1-\sin \phi^{\prime}$}

For the purpose of determining $K_{0, \mathrm{NC}}$, for the low-plasticity clay subgrade, $\phi^{\prime}=30^{\circ}$ (BSI, 2015).

Several road thicknesses were considered, overlying each subgrade model. Subgrade effective stresses varied as a result, thereby changing $z_{\mathrm{NC}}$ (Table 2).

\subsubsection{Mohr-Coulomb models}

The granular pavement was modelled as drained material with zero effective cohesion and $\phi^{\prime}=40^{\circ}$ (unless otherwise stated as $32^{\circ}$ ), roughly corresponding to typical values for a granular sub-base and general earthworks fill, respectively (BSI, 2015; Burd and Frydman, 1997; Sharp and Booker, 1984). Other 
Table 1. Parameters assumed for linear-elastic and Mohr-Coulomb models. The subgrade models were based on normally consolidated or lightly overconsolidated, soft to very soft alluvial clay of low plasticity (i.e. PI =10-15\%); $m_{1}=457 \mathrm{MPa} / \mathrm{m}$ (i.e. 0.001 $m_{1}=0 \cdot 457 \mathrm{kPa} / \mathrm{m}$ )

\begin{tabular}{lccccc} 
& $\begin{array}{c}\text { Unit weight: } \\
\mathbf{k N} / \mathbf{m}^{\mathbf{3}}\end{array}$ & $\begin{array}{c}\text { Undrained shear strength } \\
\text { at top of layer, } \boldsymbol{S}_{\mathbf{u}}: \mathbf{k P a}\end{array}$ & $\begin{array}{c}\text { Young's modulus at } \\
\text { top of layer, } \boldsymbol{E}_{\mathbf{0}}: \mathbf{M P a}\end{array}$ & $\begin{array}{c}\text { Poisson's } \\
\text { ratio, } \boldsymbol{v}\end{array}$ & $\begin{array}{c}\text { Coefficient of lateral } \\
\text { earth pressure at rest, } \boldsymbol{K}_{\mathbf{0}}\end{array}$ \\
\hline $\begin{array}{l}\text { Unbound } \\
\text { pavement, } \gamma_{\mathrm{p}}\end{array}$ & 21 & - & 50 & 0.263 & 0.36 \\
$\begin{array}{l}\text { Cohesive subgrade, } \gamma_{\mathrm{s}} \\
\text { Case 1 }\end{array}$ & 17 & & & & \\
Case 2 & 17 & $0.001 m_{1} p^{\prime}$ & $m_{1} p^{\prime}$ & 0.495 & 0.45 \\
Case 3 & 17 & 5.91 & 5.91 & 0.495 & 0.45 \\
\end{tabular}

Table 2. Model parameters assumed for various pavement designs and corresponding depths to normal consolidation required to satisfy Equation 1

\begin{tabular}{lccc}
$\begin{array}{l}\text { Pavement } \\
\text { thickness: } \boldsymbol{m}\end{array}$ & $\begin{array}{c}\text { Depth to water } \\
\text { table: } \mathbf{m}\end{array}$ & $\begin{array}{c}\mathbf{z}_{\mathbf{N C}} \text { for } \\
\text { case } \mathbf{2}: \mathbf{m}\end{array}$ & $\begin{array}{c}\boldsymbol{z}_{\mathbf{N C}} \text { for } \\
\text { case 3: } \mathbf{m}\end{array}$ \\
\hline 0.25 & 0 & 2.700 & 7.192 \\
0.50 & 0 & 2.561 & 7.053 \\
1.00 & 0 & 2.283 & 6.775 \\
1.50 & 0 & 2.005 & 6.497 \\
$0.25^{*}$ & 0.25 & 2.359 & 6.851 \\
$1.50^{*}$ & 1.50 & 1.500 & 4.450 \\
& & & \\
\end{tabular}

${ }^{*}$ Groundwater level at base of pavement

parameters were unchanged from the linear-elastic models. The clay subgrade was modelled as undrained cohesive material; that is, with $\phi^{\prime}=0$ and undrained shear strength set such that $E / S_{\mathrm{u}}=1000$, in agreement with typical values for low-plasticity, normally consolidated or lightly overconsolidated clay (D’Appolonia et al., 1971; Jamiolkowski et al., 1979).

To calculate $\omega_{\text {ult }}$, the strength reduction method (SRM) was used with a nominal surface load. The SRM reduces (or increases) strength parameters (i.e. $S_{\mathrm{u}}$ and $\tan \phi^{\prime}$ ) by an SRM factor until equilibrium is met (Midas, 2016). By modifying the surface load accordingly, an SRM factor of 1.0 was achieved, which was taken to correspond to the ultimate pressure. The bearing capacities of single-material models (drained and undrained) obtained in this manner were compared with the classical closed-form equations proposed by Brinch Hansen (1970) and were found to differ by less than $4 \%$, confirming the reasonable accuracy of the finite-element model.

To improve computational efficiency, artificial symmetry was imposed through the centreline of the wheel or vehicle. This approach is commonly used in modelling single loads (Burd and Frydman, 1997; Ismail Ibrahim, 2016) but is not necessarily applicable to a multi-wheeled vehicle as an asymmetric slip may arise between groups of wheels. To test the applicability of this simplification for closely spaced wheels, a MohrCoulomb model with artificial symmetry about the centreline

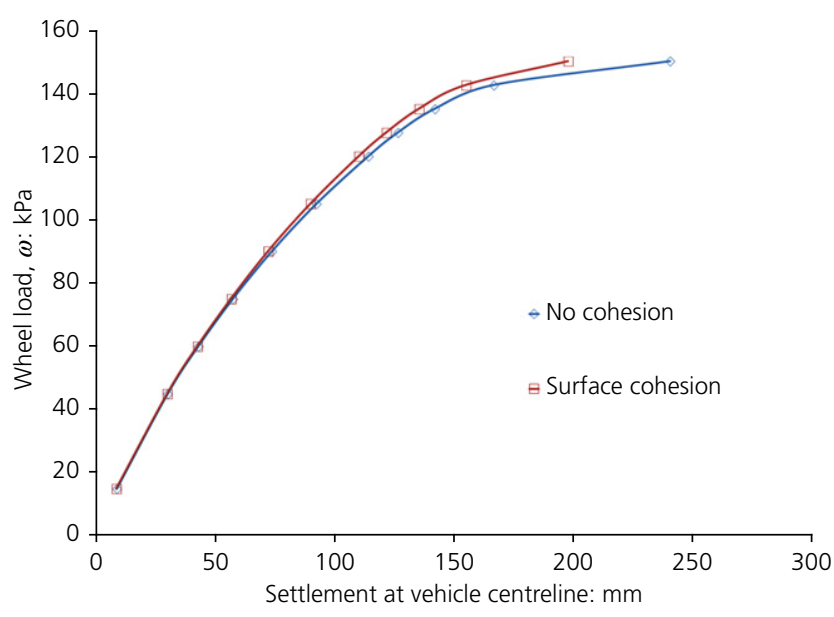

Figure 2. Load-settlement response at centreline of multi-wheel Mohr-Coulomb model for a $1.5 \mathrm{~m}$ total pavement depth, showing impact of adding cohesion to the uppermost $0.25 \mathrm{~m}$ of the pavement layer

was compared to a full-width model. The differences in bearing capacity and surface settlement profiles were found to be negligible $(<1 \%)$. The failure mechanism was found to remain symmetrical up to $95 \%$ of bearing capacity. Above this load, the solution struggled to converge and the asymmetries noted were most likely as a result of convergence algorithms rather than an asymmetrical failure mode.

For multi-wheel models with a $1.5 \mathrm{~m}$ pavement depth, large localised movement of nodes at the pavement surface adjacent to wheels caused slow convergence at low utilisations. By including a small effective cohesion of $5 \mathrm{kPa}$ over the uppermost $0.25 \mathrm{~m}$ of the $1.5 \mathrm{~m}$ thick pavement layers, convergence times were improved. A comparison of bearing capacity and settlements indicated a negligible effect on global behaviour (Figure 2).

\subsubsection{Mohr-Coulomb model with overconsolidated earth pressures}

The previous Mohr-Coulomb models only considered changes to strength and stiffness resulting from overconsolidation. The 
further refinement of including overconsolidated lateral earth pressures was thus incorporated, allowing comparison of the relative effects of lateral earth pressures on the composite response. A constant $K_{0}$ was assumed from the base of the pavement to $z_{\mathrm{NC}}$. While the actual $K_{0}$ for overconsolidated soil varies from a maximum near the surface to approach $K_{0, \mathrm{NC}}$ at depth, using a mean $K_{0}$ over the layer produces reasonable correspondence with field responses (Levenburg and Garg, 2014). The value of $K_{0}$ at the midpoint of the layer was used, calculated following Ladd et al. (1977) and Mayne and Kulhawy (1982), and assuming an exponent of $0 \cdot 8$ as per the work of Burd and Frydman (1997) (Equations 6 and 7).

$$
\text { 6. } \frac{\left(S_{\mathrm{u}} / \sigma_{\mathrm{z}}^{\prime}\right)}{\left(S_{\mathrm{u}} / \sigma_{\mathrm{z}}^{\prime}\right)_{\mathrm{NC}}}=\mathrm{OCR}^{0.8}
$$

$$
\text { 7. } \frac{K_{0, \mathrm{OC}}}{K_{0, \mathrm{NC}}}=\mathrm{OCR}^{\sin \phi}
$$

where OCR is the overconsolidation ratio. Compaction of the granular layer will 'lock in' lateral stresses (Brown, 1996). Accordingly, analyses with varying $K_{0}$ in the granular layers were undertaken (using $K_{0}=1 \cdot 0$ and $K_{0}=3 \cdot 0$ ).

\section{Modelling outcomes}

\subsection{Linear-elastic stress bulbs}

A greater relative stiffness of the pavement (i.e. over a softer subgrade) distributed vertical stress more efficiently at a wider load-spreading angle (Figure 3 and Section 2.1.2), particularly for thin pavements. Subgrade stress bulbs were also deeper for thin pavements, particularly those with high relative stiffness.

Modelling of the large multi-wheeled vehicle confirmed that the closely spaced stress bulbs beneath individual wheels join to form a resultant stress bulb on the scale of the whole vehicle (Figure 4). This acts similarly to a single load of the same width as the vehicle, meaning that even a $1.5 \mathrm{~m}$ deep pavement behaves as 'thin' in relation to the combined stress bulb, as evidenced by the wide load-spreading angle in the pavement and the deep subgrade stress bulb (similar to a single wheel load applied to a thin pavement). Changes to relative stiffness and pavement depth did not significantly affect the multiwheel stress distribution patterns (Figure 4), although deeper pavements were found to protect the subgrade from high localised stresses.

\subsection{Local yield of Mohr-Coulomb models}

The bearing capacity $\left(\omega_{\mathrm{ult}}\right)$ was found to improve at diminishing rates with increasing fill depth, eventually becoming limited by the capacity of the fill itself (Figure 5), in agreement with the findings of Burd and Frydman (1997) and Ismail
Ibrahim (2016). Limited local yielding at the pavement surface was common to all the models but was relatively small except at high utilisations (Figure 6). Local yield in the subgrade was identified when the behaviour diverged from the "pavementonly' results. Normally consolidated subgrades showed local yielding at lower utilisations, while overconsolidated subgrades showed little local yield until larger utilisations, followed by rapid plastic settlement; this is similar to the findings of D'Appolonia et al. (1971). Differences were more pronounced for thinner pavements, indicating the increased importance of the subgrade in these cases.

Single-wheel analyses with differing subgrade strengths, groundwater levels and pavement depths showed similar behaviour for similar $N_{\text {Su }}$ ratios (Figure 7); a deeper pavement or lower water table increased the subgrade effective stresses, reducing the tendency for overconsolidated-like behaviour. The pavement depth itself was also found to influence local yield. The magnitude of plastic settlement for a constant $N_{\mathrm{Su}}$ ratio reduced for a deeper pavement (compare the subgrade case 1 results in Figure 6), but the tendency for local yielding to begin at low utilisation (10-30\%) was similar.

Load-settlement behaviour of multi-wheel analyses could not be similarly normalised by $N_{\mathrm{Su}}$ at the base of the pavement (Figure 8). Following Foye et al. (2008), an influence depth for shear strength equal to one footing width (taken as the vehicle width, i.e. $6 \mathrm{~m}$ ) was used to compute $N_{\mathrm{Su}}$. The resultant values were similar to those of the normally consolidated single-wheel models (subgrade case 1), indicating that local yield behaviour is also determined by the size of the whole vehicle.

For the single-wheel analyses, increasing plastic settlement coincided with shear stresses exceeding the subgrade shear strength in the compression zone at the top of the subgrade (Figure 9). As the load increased, the yield extent spread laterally to the passive wedge zone. A similar tendency was apparent for the multi-wheel analyses, although yield occurred at low utilisations in the compression zone for all subgrade models, similarly to the normally consolidated single-wheel analyses (Figure 9).

\subsection{Development of failure mechanisms}

The form of the single-wheel failure mechanism was influenced by both the pavement thickness and $N_{\mathrm{Su}}$. Thick pavements and overconsolidated subgrades developed extension strains in a passive wedge confined to the pavement layer, while thin pavements and soft subgrades tend to develop strain bulbs in the subgrade compression zone. Figure 10 shows the progression of failure mechanisms with increasing load by indicating shear strains in excess of $1 \%$, representing significant post-yield straining. Failure mechanisms extending into overconsolidated subgrades (i.e. through thin pavements, not 


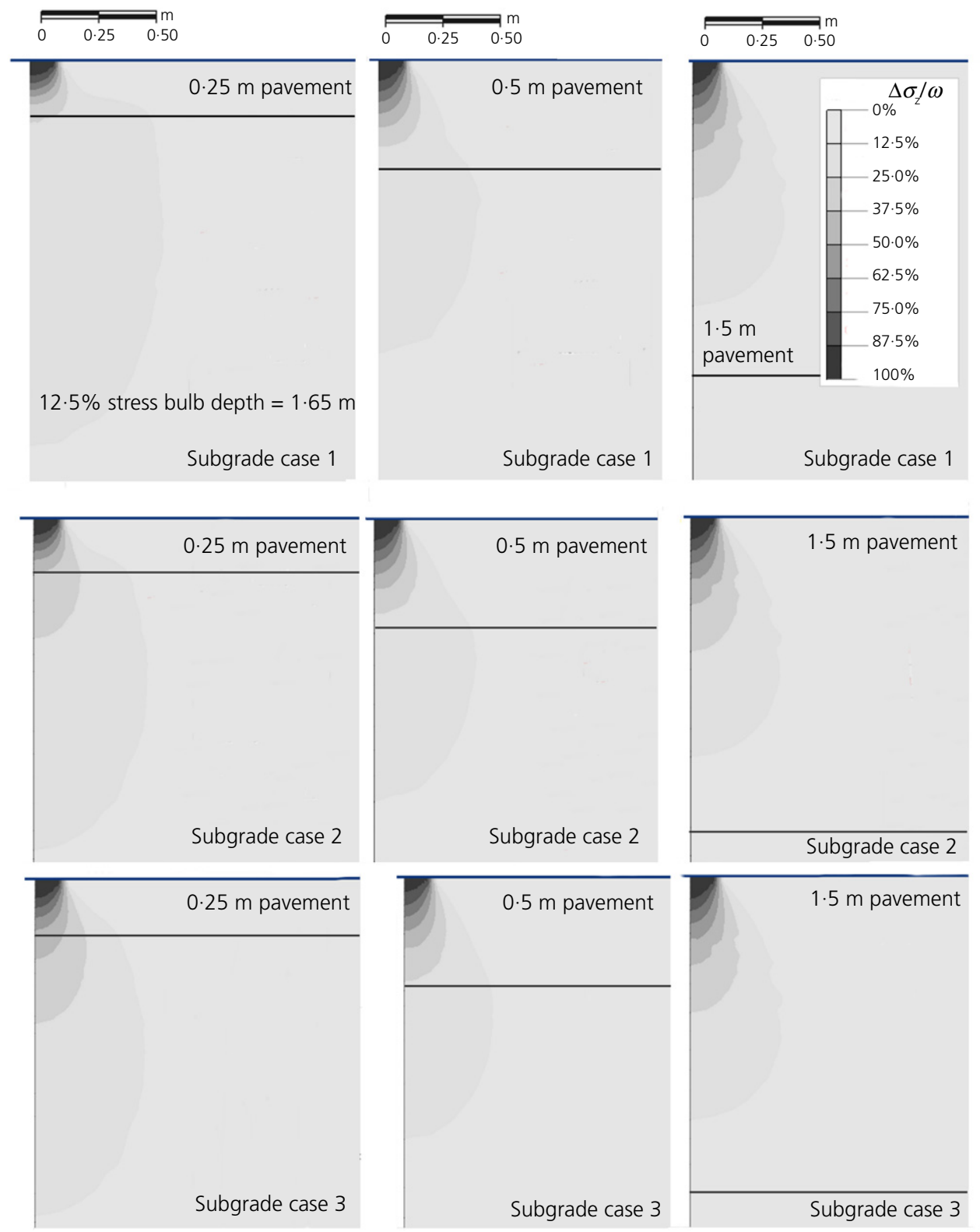

Figure 3. Increments in vertical stress, expressed as a percentage of wheel load pressure $\omega$, from a $0.25 \mathrm{~m}$ wide surface strip load with Mohr-Coulomb models of varying subgrade stiffness and pavement depth

localised to the pavement) were found to be smaller, similar to the findings of Burd and Frydman (1997).

The multi-wheel failure mechanism was governed by wheel load interactions: a single wheel load applied to a $1.5 \mathrm{~m}$ deep pavement caused failure entirely within the pavement layer (Figure 10), but the multi-wheel failure was a deep global slip over the vehicle's full width (Figure 11). The large yielded volume of soil in the compression zone was also similar to the normally consolidated single-wheel response, validating the assertion that a whole-vehicle-scale response is dominated by soil at depth and not the pavement layers (see Tables 3 and 4).

\subsection{Influence of in situ stress state}

Burd and Frydman (1997) suggested that lateral earth pressure coefficients have little effect on the ultimate bearing capacity, and the analysis from this study agrees with that suggestion. However, higher subgrade lateral earth pressures were found to reduce local yielding, in agreement with the work of 


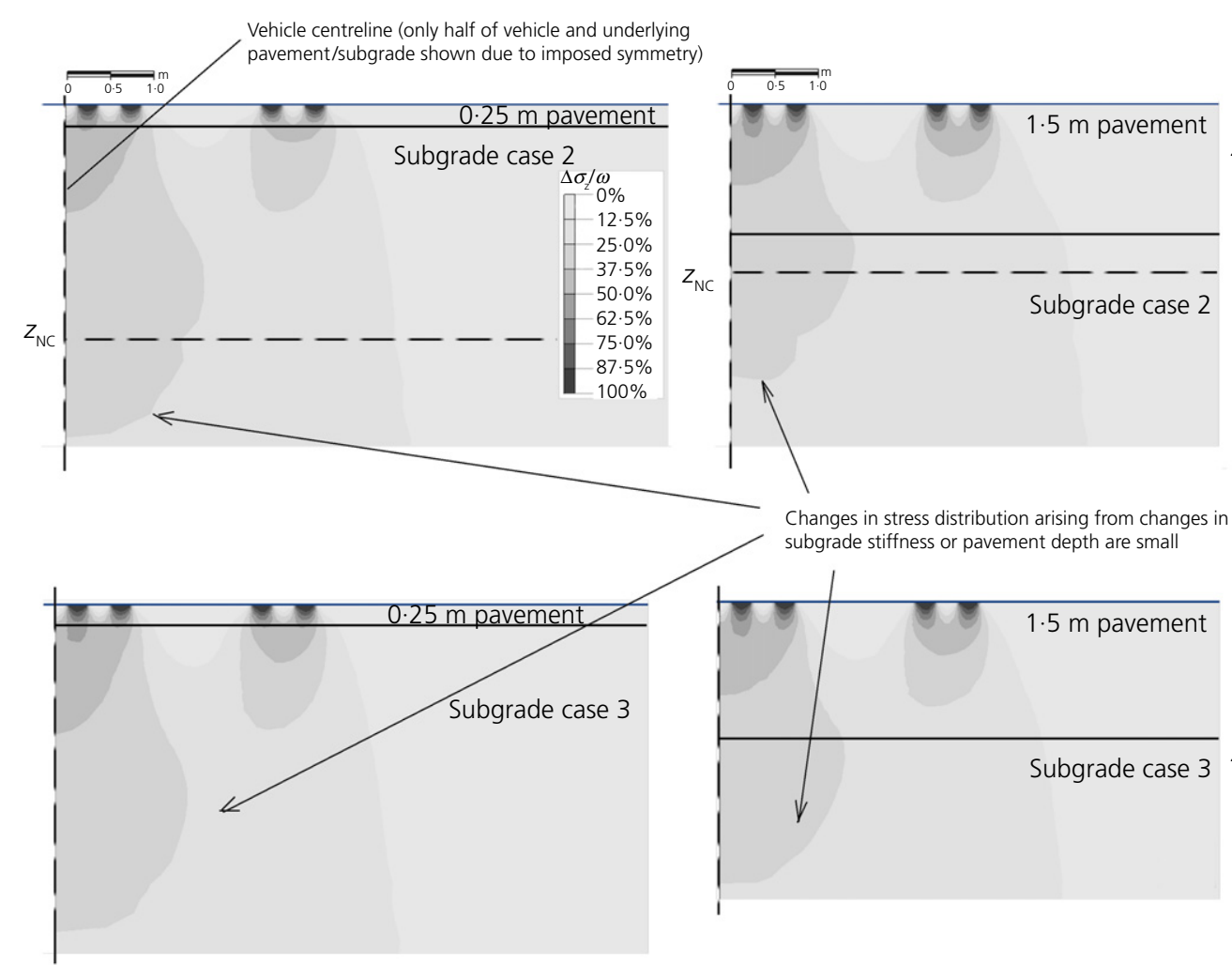

(a) (b)

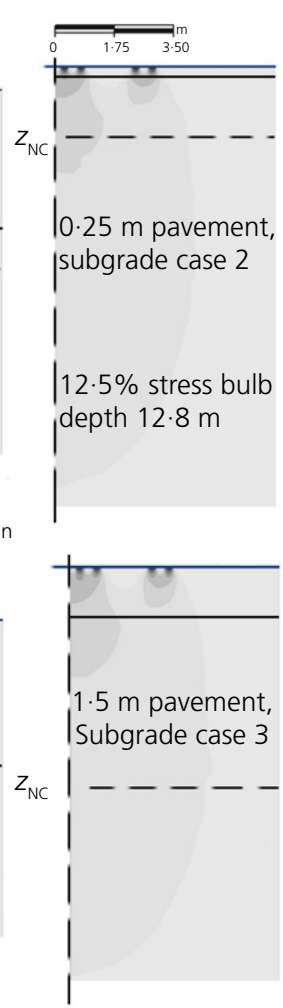

(c)

Figure 4. Increments in vertical stress, expressed as a percentage of wheel load pressure $\omega$, from a multi-wheeled vehicle with Mohr-Coulomb models of varying subgrade stiffness and pavement depth: (a) and (b) interaction between individual wheels; (c) large-scale stress bulbs over the whole-vehicle width, extending to great depth, similar to the $0.25 \mathrm{~m}$ pavement depth, subgrade case 1 stress bulbs in Figure 3

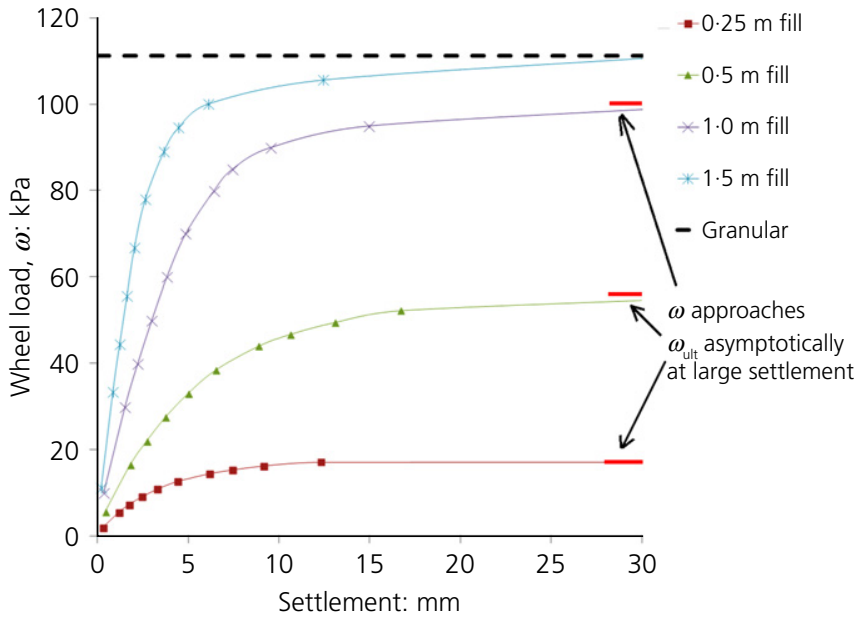

(a)

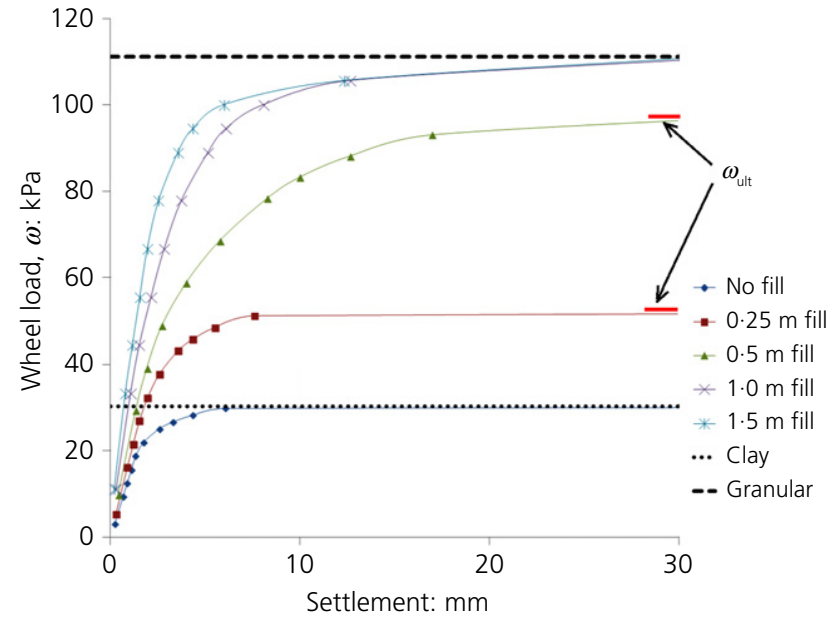

(b)

Figure 5. Load-settlement response for single-wheel models with varying pavement depths. Dashed lines indicate the closed-form capacity of the subgrade and pavement fill, calculated using the equations of Brinch Hansen (1970). (a) Subgrade case 1.

(b) Subgrade case 2 


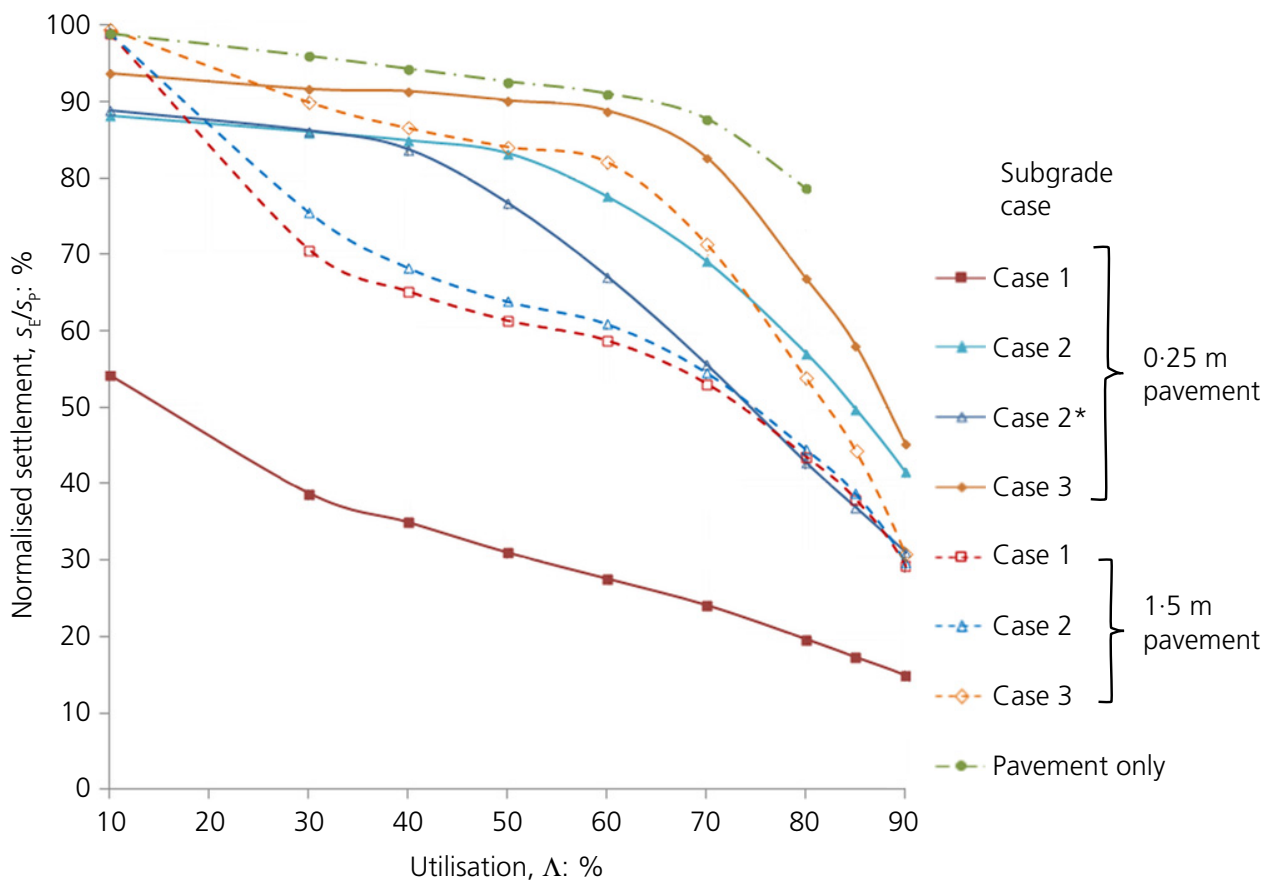

Figure 6. Normalised settlement plotted against utilisation for a range of single-wheel Mohr-Coulomb models. A normalised settlement of $100 \%$ indicates no yield (fully elastic); decreasing normalised settlement indicates increasing yield; * indicates groundwater level at base of pavement

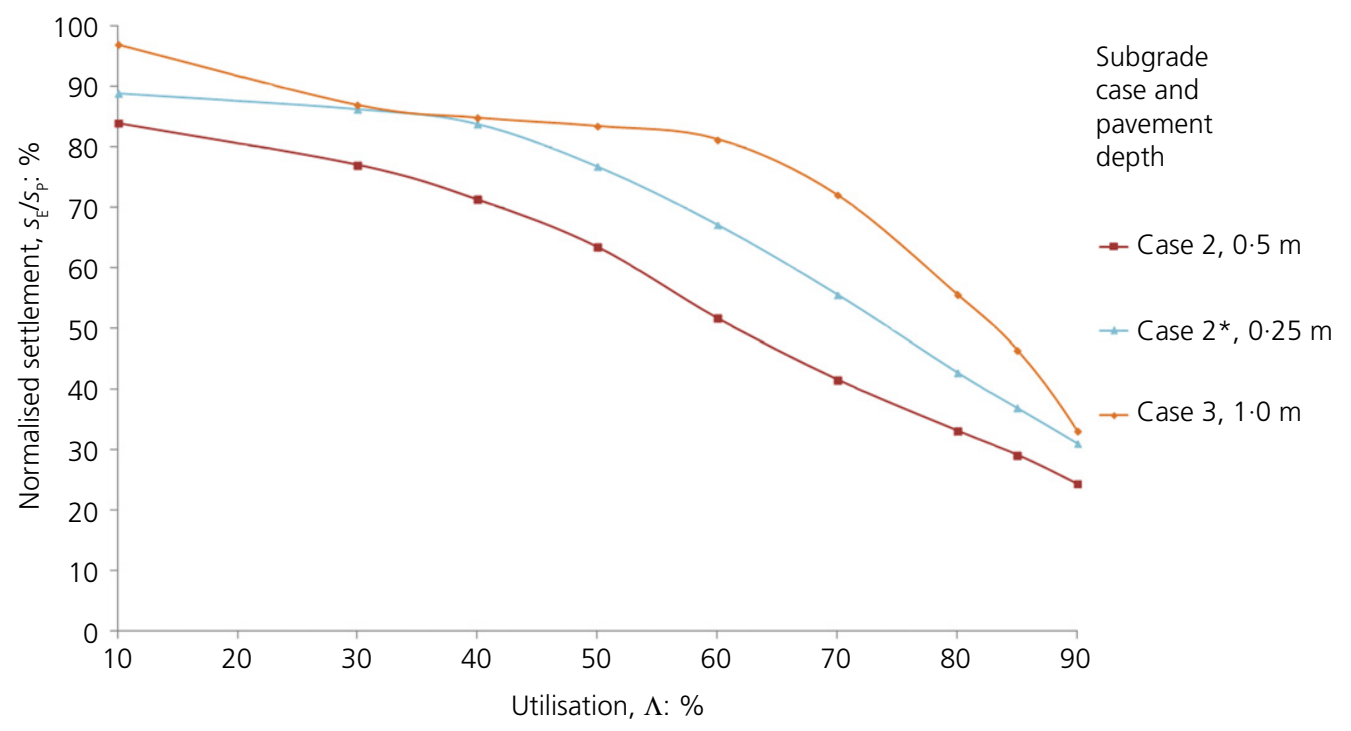

Figure 7. Normalised settlement plotted against utilisation for single-wheel Mohr-Coulomb models with similar $N_{\text {su }}$ ratios (the $N_{\text {su }}$ values were 1.06, 1.13 and 1.36); * indicates groundwater level at base of pavement

D'Appolonia et al. (1971). This was most pronounced for high overconsolidation and shallow influence depths (Figure 12), although the effect on load-settlement response was small when compared with that arising from changes in shear strength (Figure 6). For the multi-wheeled models, the behaviour was less influenced by the upper strata and hence the 


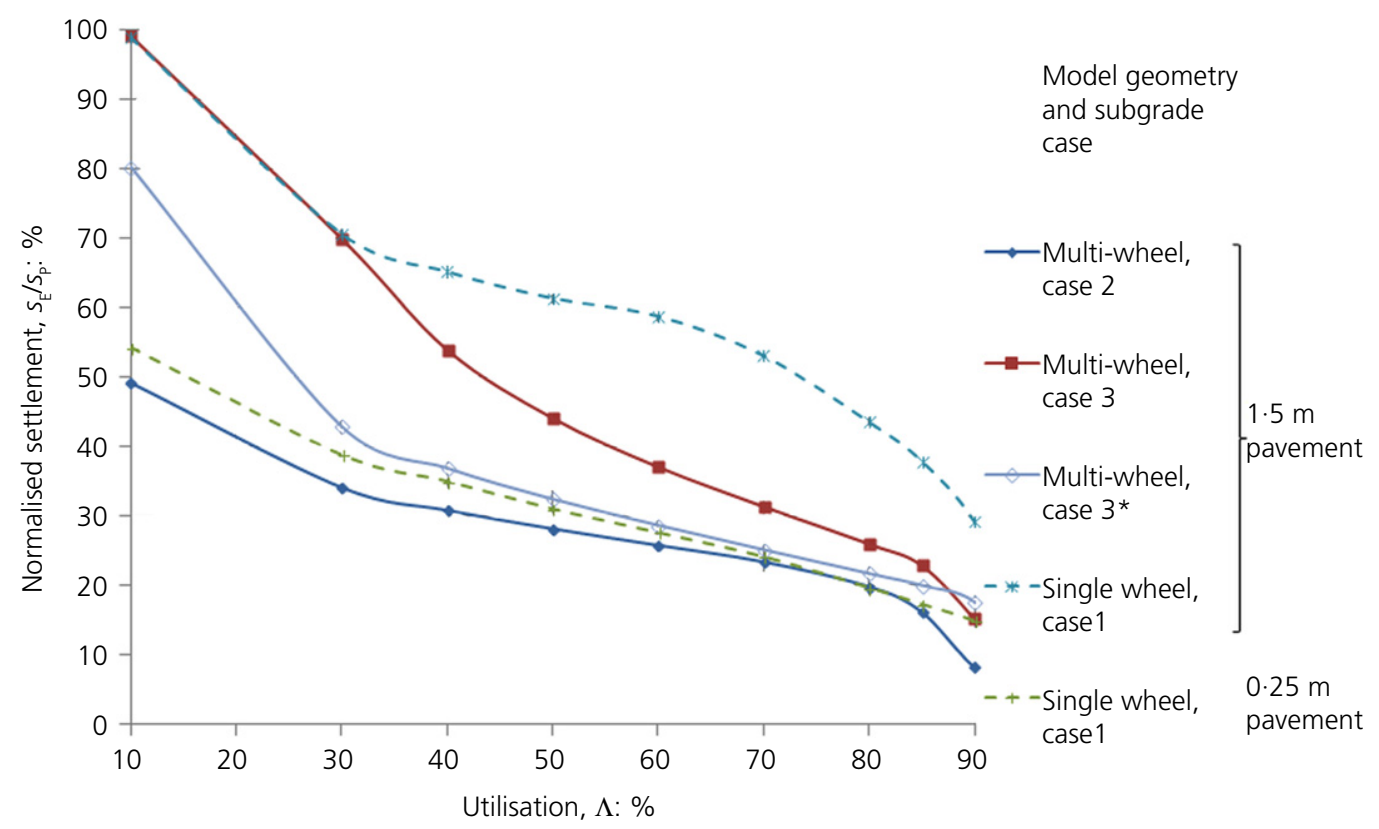

Figure 8. Normalised settlement plotted against utilisation for multi-wheel Mohr-Coulomb models with varying subgrade models. For comparison, normally consolidated (case 1) subgrade single-wheel models are also shown. Note that the shear strength and stiffness at the influence depth of $6 \mathrm{~m}$ were the same for subgrade cases $3^{*}$ and 2 (* indicates groundwater level at base of pavement)

impact of the upper overconsolidated layer was even less significant.

Increasing $K_{0}$ in the granular fill had a negligible influence on settlement. This may be due to the simplistic choice of the material model, which assumed constant stiffness. More sophisticated models (e.g. Duncan and Chang, 1970; Wolff and Visser, 1994) that account for stiffening under increasing mean normal effective stress and strain-hardening under increasing deviator stress may indicate a greater influence of $K_{0}$. This is important in understanding the response of an unbound pavement to a single wheel load (as suggested by Brown (1996)). It is likely that such sophisticated modelling of the pavement is not as necessary for large multi-wheeled vehicles because the influence of the pavement layers on the composite response is greatly reduced (Table 4).

\subsection{Comparison of principal stress rotation}

Significant rotation of the principal axes occurred within the pavement layers in front of or behind a single wheel, even at relatively low utilisations (Figure 13). Below the pavement, only small principal stress rotation occurred at low utilisation. This was more pronounced for the weaker subgrade models and can be attributed to two factors. Firstly, a lower bearing capacity (and therefore lower wheel pressures for the same degree of utilisation) means smaller relative changes to the in situ stress state. Secondly, a higher relative pavement stiffness causes greater load spreading (Figure 3), reducing the principal stress rotation in the subgrade (Figure 13). The inclination of principal stresses reduced with depth, as self-weight stresses become dominant.

For the multi-wheel model at low utilisation, the subgrade principal stresses showed little inclination, reducing further with depth and increasing with increasing utilisation. At high utilisation (80\%), a zone of principal stress reversal was apparent directly beneath the pavement (Figure 14) as the passive part of the failure mechanism was mobilised. This coincided with the development of large plastic strains throughout the entire compression zone and yield being initiated in parts of the extension zone (Figure 11).

\section{Practical considerations for heavy-haul roads}

The simplified modelling indicated that the response of an unbound pavement-subgrade system is fundamentally different when subjected to loading from a large vehicle with many closely spaced wheels rather than a single wheel. The influence of the pavement layer and the subgrade surface (dominant for the single-wheel case) is reduced and behaviour is more strongly influenced by the soil at depth (see Figures 4 and 8 and Table 4). Designing such roads by only investigating the subgrade surface and specifying a granular layer thickness to minimise irrecoverable subgrade strain from single, separate wheel loads (as is done for conventional roads) is thus inappropriate. 

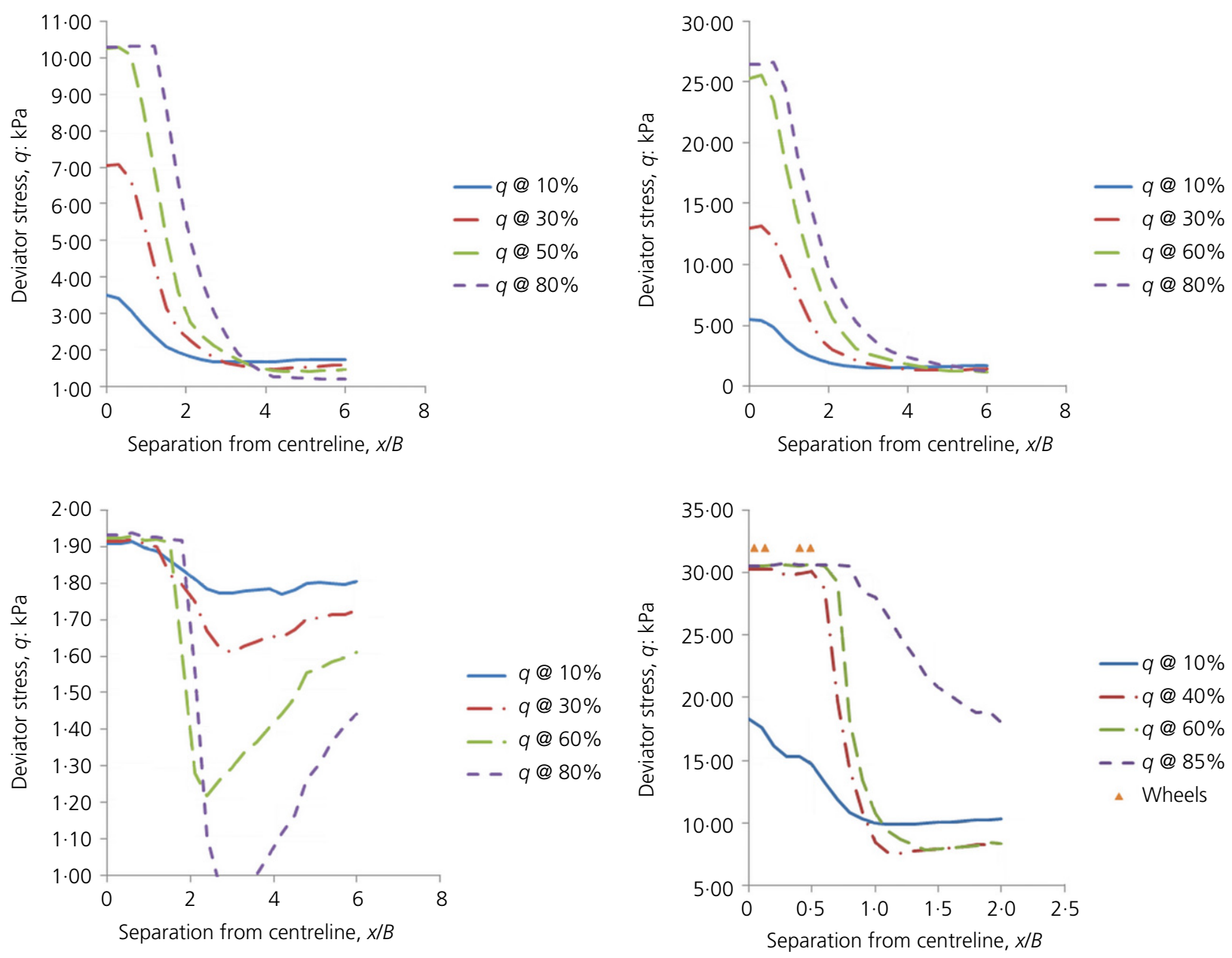

Figure 9. Deviator stress $q$ (equal to shear stress $\times 2$ ) at base of pavement layer for various degrees of utilisation $(\Lambda)$ : (a) single wheel, subgrade case 2; (b) single wheel, subgrade case 3; (c) single wheel, subgrade case 1 ; (d) multiple wheels, subgrade case 3. (a)-(c) Pavement depth $=0.25 \mathrm{~m}, B=0.25 \mathrm{~m}$. (d) Pavement depth $=1.5 \mathrm{~m}, B$ assumed to be $6 \mathrm{~m}$ (whole-vehicle width)

A different site investigation and design approach is therefore necessary for roads carrying large multi-wheeled vehicles. Surface tests, such as the commonly used CBR test, dynamic probing or in situ surface stiffness tests (Frost, 2000), will still be useful in understanding resistance to rutting on the scale of a single wheel but less useful in understanding the behaviour of deeper soils when exposed to repetitions of multi-wheeled vehicles. The risk of degradation due to a whole-vehicle-scale mechanism will require investigation to greater depths using investigation techniques more common to the design of large foundations, such as percussive drilling or cone penetration tests. Furthermore, monitoring of pavement surfaces for rutting may not give an indication of deeper-seated strain development, which is likely to manifest over a larger area. Under large strains close to or exceeding yield, excess pore water pressures are expected to accumulate in the subgrade; monitoring pore water pressures at depth by way of piezometers in boreholes may therefore be more effective.
The finite-element results suggest that a large vehicle will generate local yielding at much lower utilisations (Figures 8 and 11). As shakedown theory indicates that cyclic failure is expected at loads slightly in excess of those causing the first local yield, a conventional design that aims to avoid cyclic degradation would need to limit the extents of yielding, either through a very deep pavement or high earthworks to spread transient stresses sufficiently, or by strengthening the ground with large-scale ground improvement. Both of these options are unlikely to be economically viable for a temporary road.

The excess pore water pressures generated by a single vehicle passage may initially reduce the strength of the subgrade, potentially making it unsafe for another vehicle to pass. However, consolidation of the subgrade is expected to increase its strength over time. By taking this into account, an economic observational design, similar in philosophy to that 

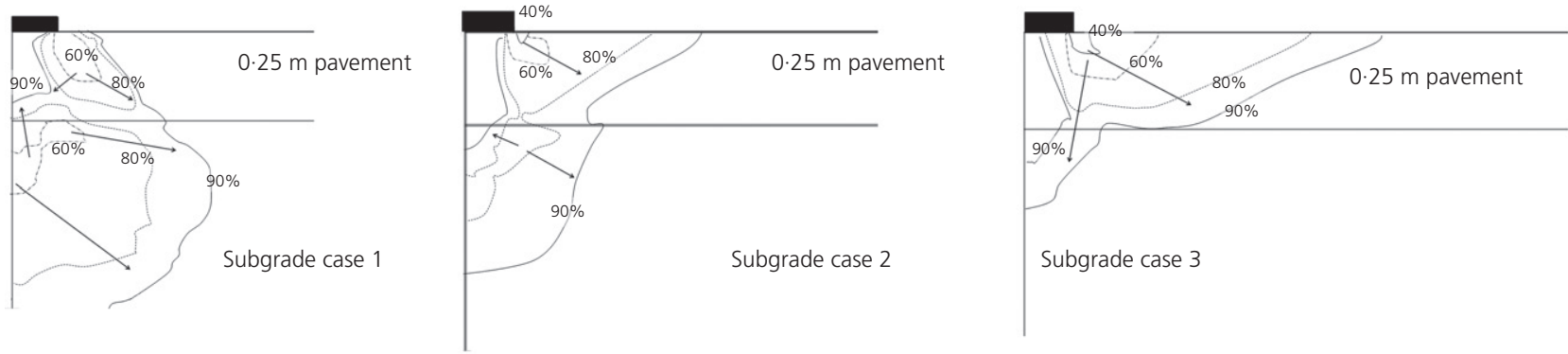

(Arrows indicate spread of yielded zone)
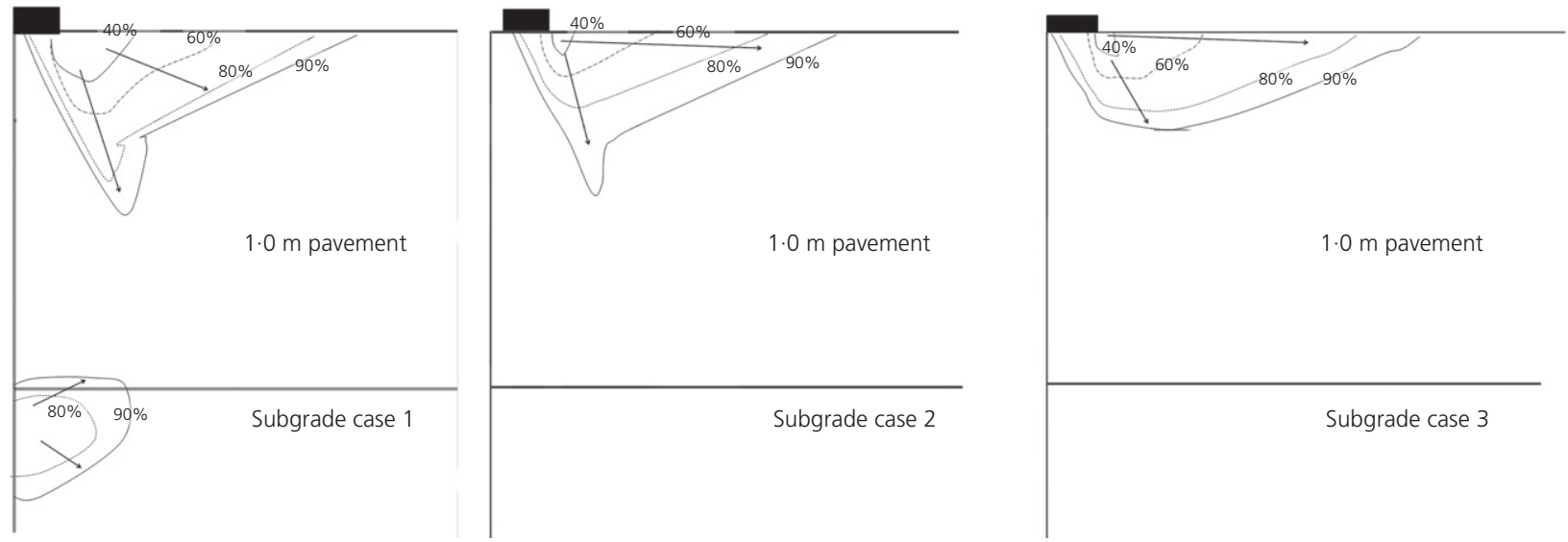

Figure 10. Progression of failure mechanisms indicated by $1 \%$ shear strain (i.e. large post-yield strain) contours for various degrees of utilisation (shown as percentage values on the plots) for single-wheel Mohr-Coulomb models

of the Cape Kennedy causeway to transport Apollo mission rockets (Peck, 1969), could be achieved: vehicles only traverse once the subgrade strength has sufficiently recovered. For this approach, the following aspects of subgrade behaviour, discussed further by Krechowiecki-Shaw et al. (2016), need to be understood.

- The rate at which consolidation occurs: monitoring in situ pore water pressures during operations would be more effective than estimation from laboratory tests on recovered samples and would provide a real-time indication of risk.

- Strength recovery as a function of excess pore water pressure dissipation: advanced laboratory testing will be required to determine the degree of consolidation necessary to recover the soil's initial strength fully. This can then be used as a trigger level to allow passage of the next heavy vehicle.

If this approach is used, large strains are likely to develop (at least initially). Topping up of the pavement surface may be necessary to maintain design alignment. An additional complication arises if this design approach is used to mobilise high proportions of capacity and the compression zone of the failure mechanism fully yields (Figure 11). Resistance to a failure mechanism is then provided by the 'passive' extension zone away from the loaded area. Not only is stability wholly dependent upon the strength of the extension zone being maintained, but the greater rotation of principal stresses (Figure 13) will also accelerate cyclic degradation. The response of soil to such an extreme combination of actions is not well understood and further research into this is merited.

\section{Conclusions}

The simple material models used in the finite-element analyses presented in this paper are easy to understand and apply, and the effects of yield can be isolated and investigated. It is recognised that these models are not representative of real soil behaviour, which often exhibits features such as strain- and pressure-dependent stiffness. Further investigations, isolating the effects of these properties, will be useful in developing a more realistic picture of a soil's response. However, the modelling undertaken in this study clearly indicates that the composite pavement-subgrade response for a multi-wheeled large vehicle is fundamentally different to that of a conventional vehicle. Road design must therefore consider the following issues. 
Transport

Volume 171 Issue TR1
Routes for exceptional loads: a new soil mechanics perspective

Krechowiecki-Shaw, Royal, Jefferson and

Ghataora
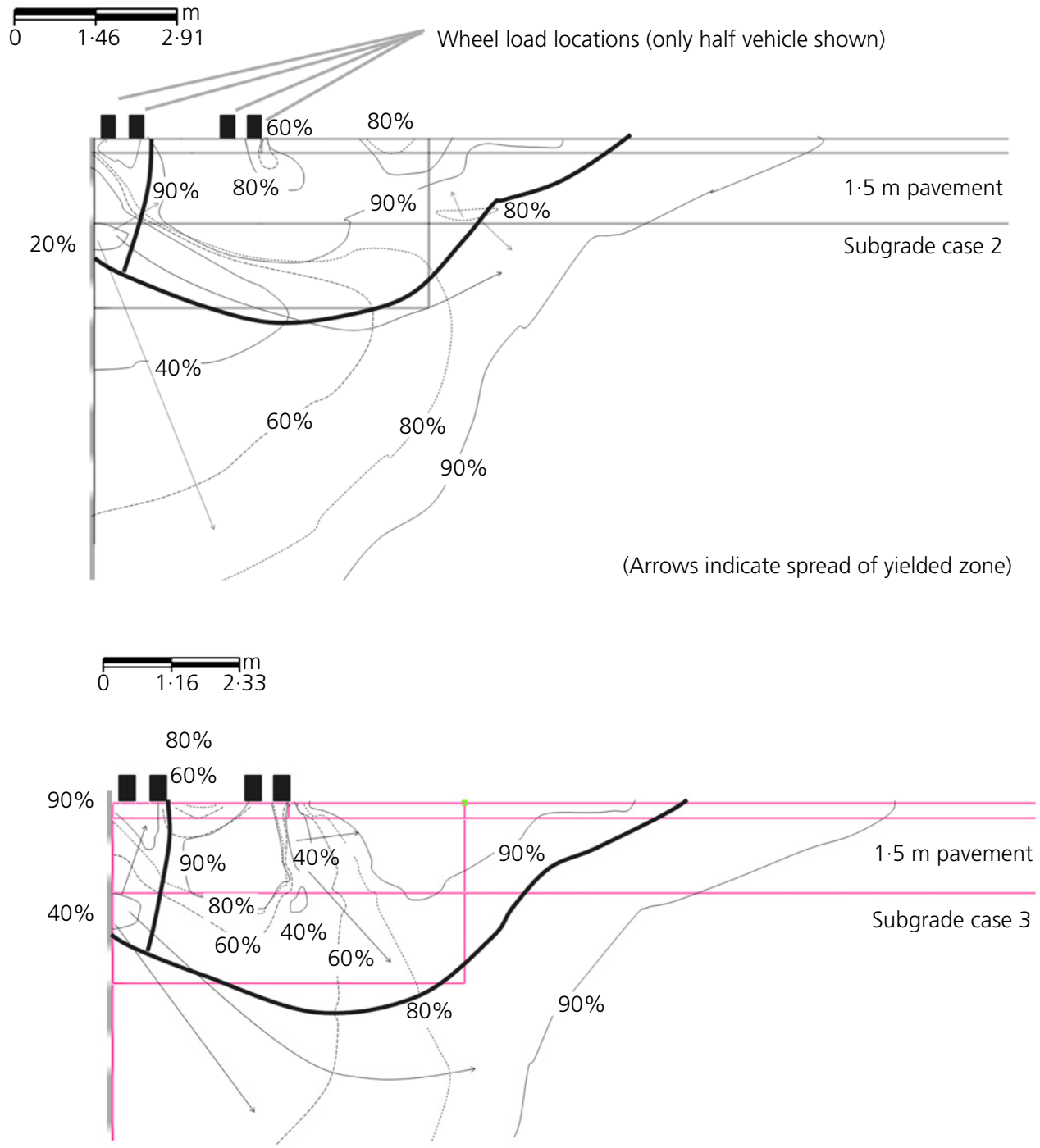

Figure 11. Progression of failure mechanisms indicated by $1 \%$ shear strain contours for various degrees of utilisation (shown as percentage values on the plots) for multi-wheel Mohr-Coulomb models. The thick lines follow the maximum shear strains developed at $95 \%$ utilisation (i.e. approximate to the final failure mechanism)

Table 3. Ultimate wheel pressures from finite-element single- and multi-wheel models. The bearing capacity of the pavement-only singlewheel model is $111 \mathrm{kPa}$

\begin{tabular}{ccccc} 
& & \multicolumn{2}{c}{ Ultimate wheel pressure, $\omega_{\text {ult }}: \mathbf{k P a}$} & Ratio of ultimate pressures \\
\cline { 2 - 4 } (case 3/case 2)
\end{tabular}

more influential. The composite system responds on a whole-vehicle scale, similar to the response of a single
wheel load applied to a thin pavement. Local yielding whole-vehicle scale, similar to the response of a single
wheel load applied to a thin pavement. Local yielding closer to a normally consolidated state and more prone to local compressive yielding) being mobilised and is thus far 
Table 4. Ultimate wheel pressures for single- and multi-wheel models with varying pavement strength parameters

\begin{tabular}{|c|c|c|c|}
\hline \multirow[b]{2}{*}{ Subgrade model } & \multirow[b]{2}{*}{ Pavement depth: $m$} & \multicolumn{2}{|c|}{$\omega_{\text {ult }}: \mathrm{kPa}$} \\
\hline & & Pavement $\phi^{\prime}=40^{\circ}$ & Pavement $\phi^{\prime}=32^{\circ}$ \\
\hline Single wheel, subgrade case 1 & 0.25 & 18 & 13 \\
\hline Single wheel, subgrade case 2 & 0.25 & 54 & 29 \\
\hline Single wheel, subgrade case $2^{*}$ & 0.25 & 63 & 48 \\
\hline Multiple wheels, subgrade case 2 & $1 \cdot 5$ & 197 & 169 \\
\hline Multiple wheels, subgrade case 3 & $1 \cdot 5$ & 320 & 290 \\
\hline Multiple wheels, subgrade case $3^{*}$ & 1.5 & 340 & 320 \\
\hline
\end{tabular}

${ }^{*}$ Groundwater level at base of pavement

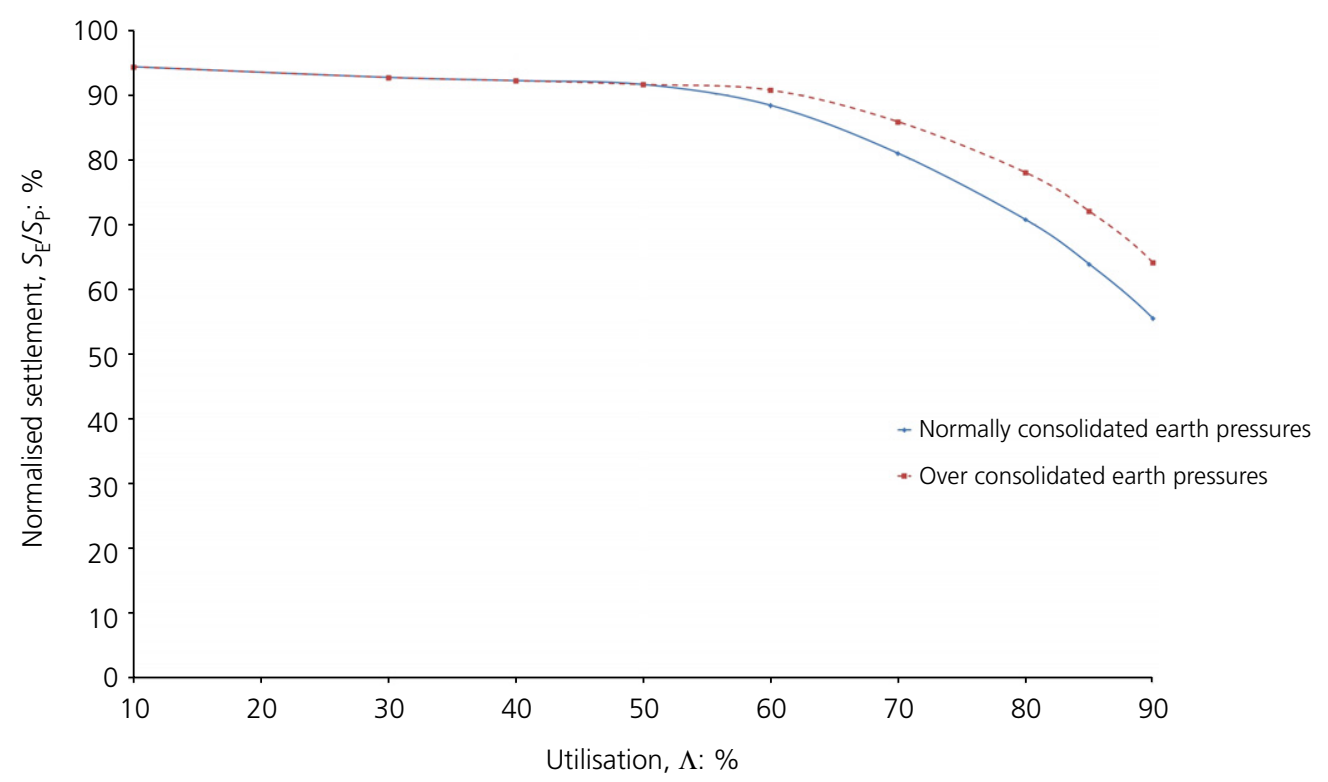

Figure 12. Normalised settlement plotted against utilisation plots for Mohr-Coulomb single-wheel models of subgrade case $3 *$ (i.e. groundwater at base of pavement) with pavement depth of $0.25 \mathrm{~m}$ and varying coefficients of lateral earth pressure in the overconsolidated portion of the subgrade layer

behaviour can be described by assuming an influence depth equal to the vehicle width, as proposed by Foye et al. (2008) for shallow foundations. The pavement and upper overconsolidated subgrade layers are less influential for large multi-wheeled vehicles.

- Principal stress rotation from moving wheel loads is known to accelerate degradation significantly. This will complicate the degradation regime under a large heavy vehicle; soil at depth is expected to be less affected by stress rotation than surface soils due to the higher self-weight stresses.

However, if loads close to the static bearing capacity are transported, a passive wedge begins to mobilise, resulting in significant principal stress rotations extending to depth. As the passive wedge provides the final restraint against failure, rapid strength degradation here could result in sudden collapse. Further research into soil under such extreme conditions is required.
- Limiting the subgrade to small-strain behaviour to avoid degradation under repeated transient load may be unfeasible for a temporary road; the large factors of safety necessary (in the region of 3 to 10) may not be economically justifiable.

- Conventional investigation and design, while useful for designing pavement layers to resist rutting along wheel tracks, is governed by the properties of the subgrade surface and does not give adequate understanding of deeper-seated risks.

In contrast to the conventional design method, it is recommended that deep investigation (similar to that used for large shallow foundations) and in-service monitoring of deep subsoils are conducted to understand the real-time risk of strength degradation. A design that allows repeated application of medium to large strains is expected to result in significant changes to the subgrade. If the interaction between 
Transport

Volume 171 Issue TR1
Routes for exceptional loads: a new soil

mechanics perspective

Krechowiecki-Shaw, Royal, Jefferson and

Ghataora
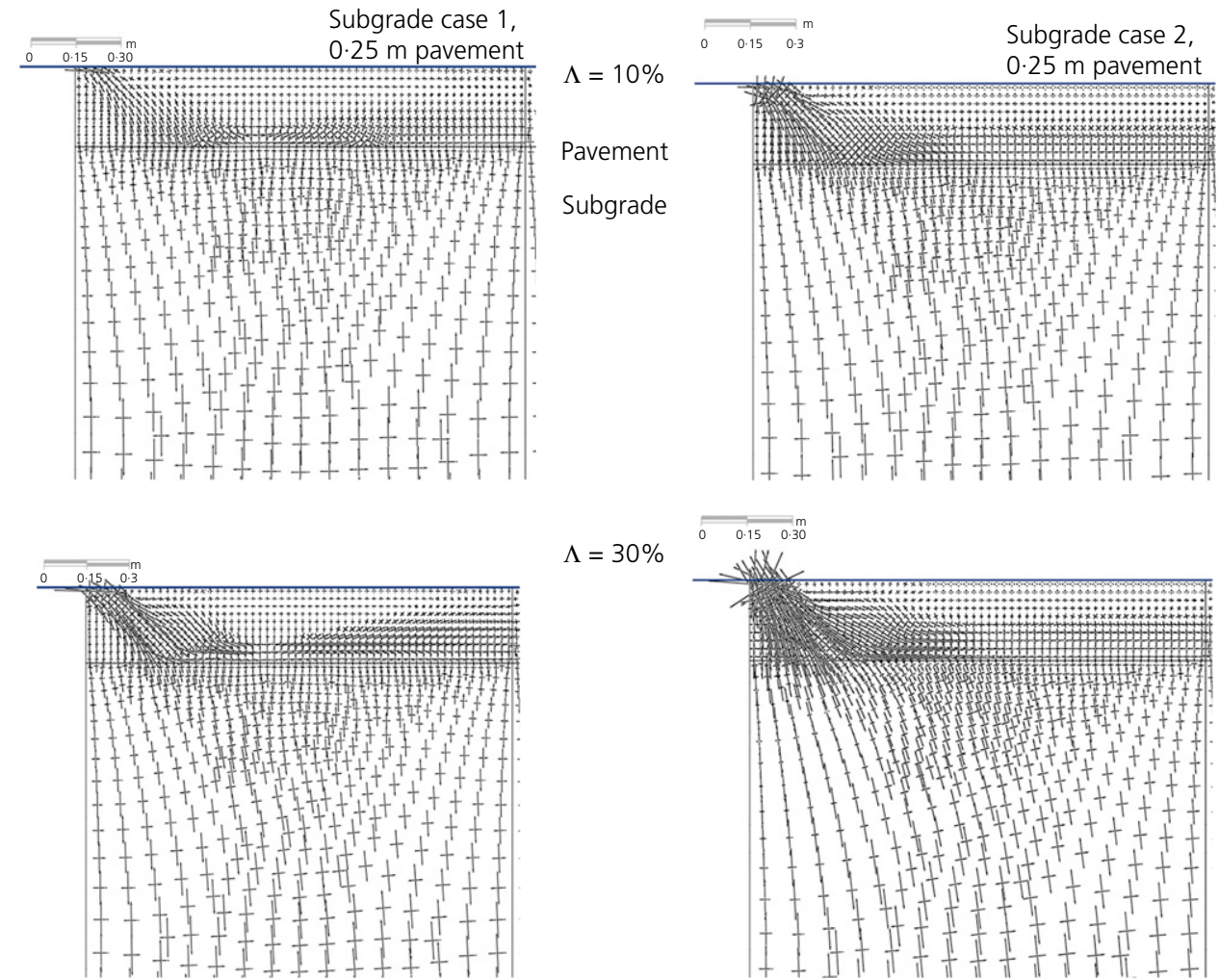

$\Lambda=30 \%$
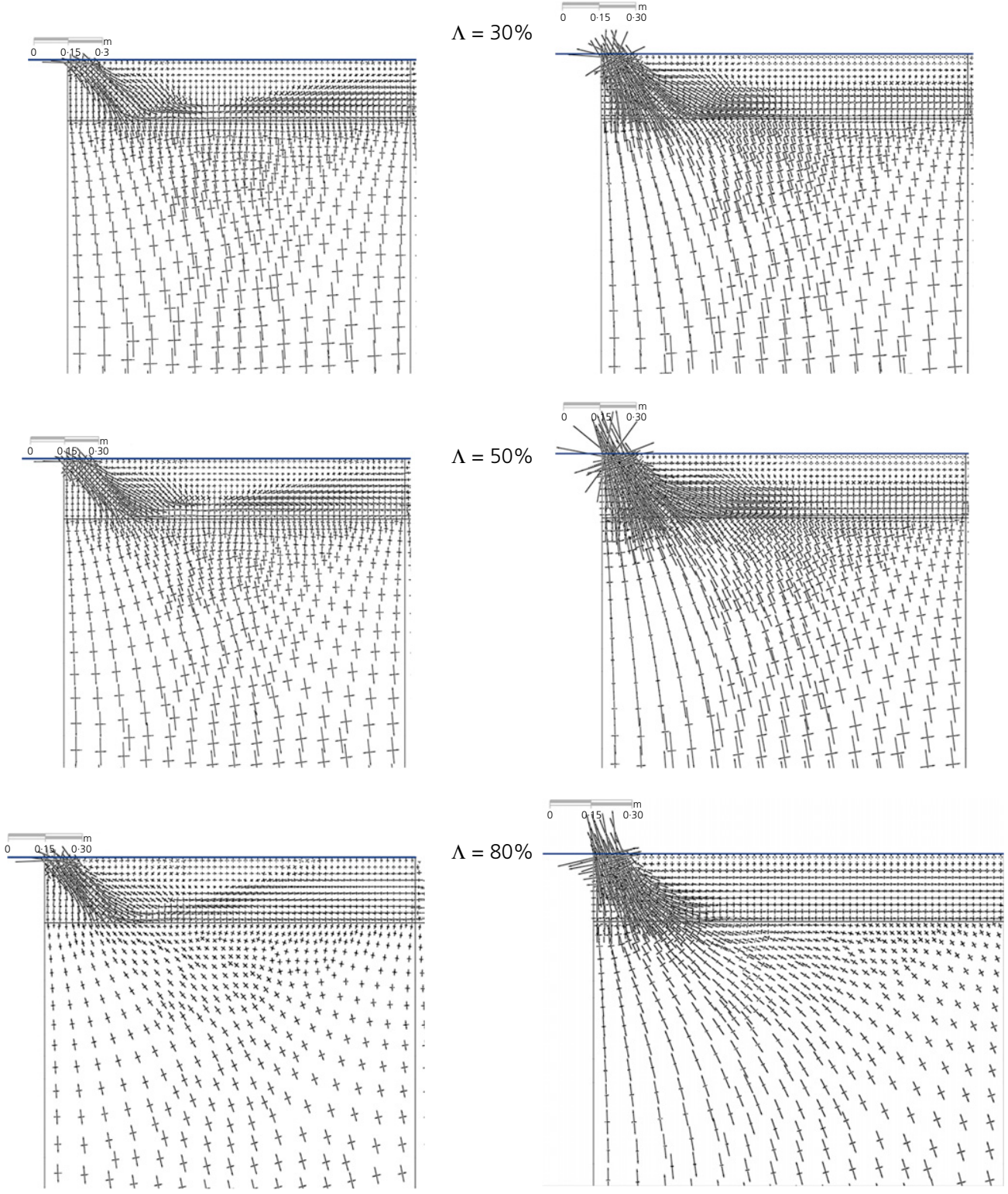

Figure 13. Principal stress vectors (i.e. line length $=$ stress magnitude, rotation $=$ stress direction) for single-wheel Mohr-Coulomb models with varying degrees of utilisation $(\Lambda)$. A vector aligned horizontally and vertically but where the horizontal vector is larger indicates a rotation of $90^{\circ}$ (i.e. full principal stress reversal) 
Routes for exceptional loads: a new soil mechanics perspective

Krechowiecki-Shaw, Royal, Jefferson and Ghataora
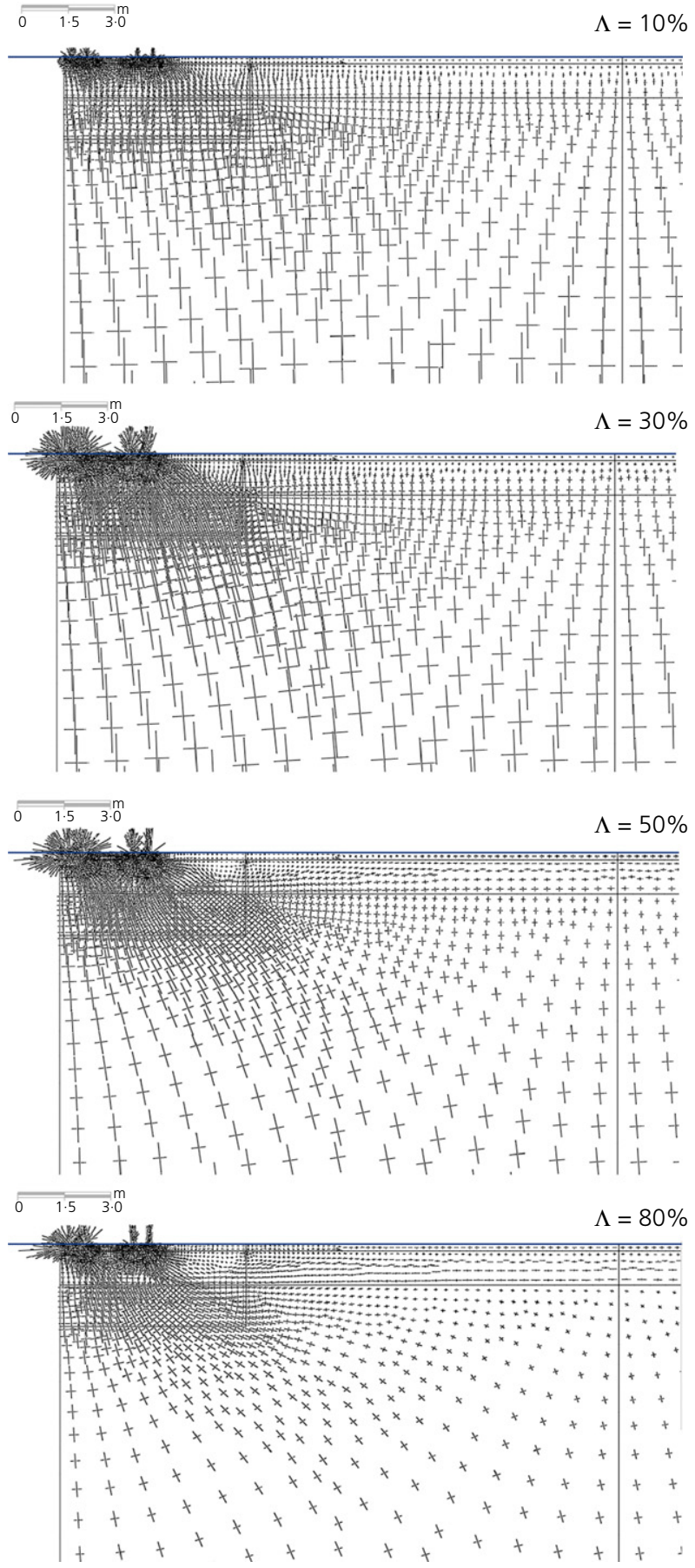

Figure 14. Principal stress vectors (i.e. line length $=$ stress magnitude, rotation = stress direction) for multi-wheel MohrCoulomb model with subgrade case 3 and a $1.5 \mathrm{~m}$ pavement depth, with varying degrees of utilisation $(\Lambda)$. A vector aligned horizontally and vertically but where the horizontal vector is the larger indicates a rotation of $90^{\circ}$ (i.e. full principal stress reversal)

degradation and consolidation-related strengthening over time is understood and the risks are well managed, significant construction cost benefits are possible.

\section{Acknowledgements}

The authors acknowledge the financial support for this research provided by the University of Birmingham and the Engineering and Physical Sciences Research Council (EPSRC).

\section{REFERENCES}

Arthur JR, Rodriguez JI, Dunstan T and Chua KS (1980) Principal stress rotation: a missing parameter. ASCE Journal of the Geotechnical Engineering Division 106(4): 419-433.

Berardi R and Lancellotta R (2002) Yielding from field behaviour and its influence on oil tank settlements. ASCE Journal of Geotechnical and Geoenvironmental Engineering 128(5): 404-415.

Boulbibane M, Collins IF, Ponter ARS and Weichert D (2005) Shakedown of unbound pavements. Road Materials and Pavement Design 6(1): 81-96.

Brinch Hansen J (1970) A Revised and Extended Formula for Bearing Capacity. Danish Geotechnical Institute, Copenhagen, Denmark, Bulletin No. 28.

Brooker EW and Ireland HO (1965) Earth pressures at rest related to stress history. Canadian Geotechnical Journal 2(1): 1-15.

Brown SF, Andersen KH and McElvaney J (1977) The effect of drainage on cyclic loading of clay. Proceedings of the 9 th International Conference of Soil Mechanics and Foundation Engineering, Tokyo, Japan, vol. 2, pp. 195-200.

Brown SF (1996) Soil mechanics in pavement engineering. Géotechnique 46(3): 383-426, http://dx.doi.org/10.1680/geot.1996.46.3.383.

Brown SF and Chan FWK (1996) Reduced rutting in unbound granular pavement layers through improved grading design. Proceedings of the Institution of Civil Engineers - Transport 117(1): 40-49, http://dx.doi.org/10.1680/itran.1996.28142.

BSI (2015) BS 8002:2015: Code of practice for earth retaining structures. BSI, London, UK.

Burd HJ and Frydman S (1997) Bearing capacity of plane-strain footings on layered soils. Canadian Geotechnical Journal 34(2): 241-253.

Cronin B (2015) Prefab progression. New Civil Engineer, 10 September: pp. 28-30.

D'Appolonia DJ, Poulos HG and Ladd CC (1971) Initial settlement of structures on clay. ASCE Journal of the Soil Mechanics and Foundations Division 97(10): 1359-1377.

Díaz-Rodriguez JA and López-Molina JA (2008) Strain thresholds in soil dynamics. Proceedings of the 14th World Conference on Earthquake Engineering, Beijing, China, paper no. 04-01-0037.

Duncan JM and Chang CM (1970) Nonlinear analysis of stress and strain in soils. ASCE Journal of Soil Mechanics and Foundations Division 96(SM5): 1629-1653.

FCE (Forestry Commission England) (2011) Grants \& Regulations Operations Note 25: Forest Roads and Tracks. FCE, Bristol, UK.

Foye KC, Basu P and Prezzi M (2008) Immediate settlement of shallow foundations bearing on clay. ASCE International Journal of Geomechanics 8(5): 300-310.

Frost MW (2000) The Performance of Pavement Foundations During Construction. PhD thesis, Loughborough University, Loughborough, UK.

Frost MW, Fleming PR and Rogers CDF (2004) Cyclic triaxial tests on clay subgrades for analytical pavement design. ASCE Journal of Transportation Engineering 130(3): 378-386.

Gräbe PJ and Clayton CRI (2009) Effects of principal stress rotation on permanent deformation in rail track foundations. ASCE Journal of Geotechnical and Geoenvironmental Engineering 135(4): 555-566.

Heath DL, Shenton MJ, Sparrow RW and Waters JM (1972) Design of conventional rail track foundations. Proceedings of the Institution of Civil Engineers 51(2): 251-267, http://dx.doi.org/10.1680/iicep. 1972.5952 .

Houlsby GT and Burd H (1999) Understanding the behaviour of unpaved roads on soft clay. Proceedings of the 12th European Conference on 
Soil Mechanics and Foundation Engineering, Amsterdam, the Netherlands, pp. 31-44.

Hyde AFL (1974) Repeated Load Triaxial Testing of Soils. PhD thesis, University of Nottingham, Nottingham, UK.

Ismail Ibrahim KMH (2016) Bearing capacity of circular footing resting on granular soil overlying soft clay. HBRC Journal 12(1): 71-77.

Jaky J (1948) Pressure in silos. Proceedings of the 2nd International Conference in Soil Mechanics and Foundation Engineering, Rotterdam, the Netherlands, pp. 103-107.

Jamiolkowski M, Lancellotta R, Pasqualini E, Marchetti S and Nova R (1979) Design parameters for soft clays. General report.

Proceedings of the 7th European Conference on Soil Mechanics and Foundation Engineering, vol. 1, pp. 103-107.

Jefferies M, Shuttle D and Been K (2015) Principal stress rotation as cause of cyclic mobility. Geotechnical Research 2(2): 66-96.

Juspi S (2007) Experimental Validation of the Shakedown Concept for Pavement Analysis and Design. $\mathrm{PhD}$ thesis, University of Nottingham, Nottingham, UK.

Kaufman WW and Ault JC (1977) Design of Surface Mine Haulage Roads - A Manual. United States Department of the Interior, Washington, DC, USA, Information Circular 8758.

Krechowiecki-Shaw CJ, Jefferson I, Royal ACD, Ghataora GS and Alobaidi IM (2016) Degradation of soft subgrade soil from slow, large, cyclic heavy haul road loads: a review. Canadian Geotechnical Journal 53(9): 1435-1449.

Ladd CC, Foott R, Ishihara K, Poulos HG and Schlosser F (1977) Stress-deformation and strength characteristics. State of the art report in session 1. Proceedings of the 11th International Conference on Soil Mechanics and Foundation Engineering, Tokyo, Japan, pp. 421-494.

Laman M, Yildiz A, Ornek M and Demir A (2012) Field test of circular footings on reinforced granular fill layer overlying a clay bed. Geotechnical Testing Journal 35(4): GTJ103512.

Lehtonen VJ, Meehan CL, Länsivaara TT and Mansikkamäki JN (2015) Full-scale embankment failure test under simulated train loading. Géotechnique 65(12): 961-974, http://dx.doi.org/10.1680/ jgeot.14.P.100.

Levenburg E and Garg N (2014) Estimating the coefficient of at-rest earth pressure in granular pavement layers. Transportation Geotechnics 1(1): 21-30.

Little PH (1992) The Design of Unsurfaced Roads Using Geosynthetics. $\mathrm{PhD}$ thesis, University of Nottingham, Nottingham, UK.

Madabhushi SSC and Haigh SK (2015) Investigating the changing deformation mechanism beneath shallow foundations. Géotechnique 65(8): 684-693, http://dx.doi.org/10.1680/ geot.14.P.226.
Mammoet (2017) http://www.mammoet.com/en/cases (accessed 21/04/2017)

Mayne PW and Kulhawy FH (1982) $\mathrm{K}_{0}$-OCR relationships in soil. ASCE Journal of Geotechnical Engineering 108(6): 851-872.

Midas (2016) GTS NX Software Online Manual. MIDAS Information Technology Co., Ltd., Seongnam, Korea. See http://manual. midasuser.com/en_common/GTS \%20NX/150/GTX.htm (accessed 29/06/2016).

Osman AS and Boulton MD (2005) Simple plasticity-based prediction of the undrained settlement of shallow circular foundations on clay. Géotechnique 55(6): 435-447, http://dx.doi.org/10.1680/geot.2005. 55.6.435.

Pande GN (1982) Shakedown of foundations subjected to cyclic loads. In Soil Mechanics - Transient and Cyclic Loads (Pande GN and Zienkiewicz OC (eds)). Wiley, Chichester, UK, pp. 219-252.

Peck RB (1969) Advantages and limitations of the observational method in applied soil mechanics. Géotechnique 19(2): 171-187, http://dx.doi.org/10.1680/geot.1969.19.2.171.

Ponter ARS, Hearle AD and Johnson KL (1985) Application of the kinematical shakedown theorem to rolling and sliding point contacts. Journal of the Mechanics and Physics of Solids 33(4): 339-362.

Schofield A and Wroth P (1968) Critical State Soil Mechanics. McGraw Hill, London, UK.

Sharp RW and Booker JR (1984) Shakedown of pavements under moving surface loads. ASCE Journal of Transportation Engineering 110(1): $1-14$.

Tannant DD and Regensburg B (2001) Guidelines for Mine Haul Road Design. University of British Columbia, Okanagan, BC, Canada.

Wang S, Onyejekwe S and Yang J (2014) Threshold strain for postcyclic shear strength change of Mississippi River Valley silt due to cyclic triaxial loading. Journal of Testing and Evaluation 42(1): 1-9.

Wolff $\mathrm{H}$ and Visser A (1994) Incorporating elasto-plasticity in granular layer pavement design. Proceedings of the Institution of Civil Engineers - Transport 105(4): 259-272, http://dx.doi.org/10.1680/ itran.1994.27137.

Xiao J, Juang CH, Wei K and Xu S (2014) Effects of principal stress rotation on the cumulative deformation of normally consolidated soft clay under subway traffic loading. ASCE Journal of Geotechnical and Geoenvironmental Engineering 140(4): 04013046.

Zhao J, Sloan SW, Lyamin AV and Krabbenhøft K (2008) Bounds for shakedown of cohesive-frictional materials under moving surface loads. International Journal of Solids and Structures 45(11): $3290-3312$.

\section{How can you contribute?}

To discuss this paper, please email up to 500 words to the editor at journals@ice.org.uk. Your contribution will be forwarded to the author(s) for a reply and, if considered appropriate by the editorial board, it will be published as discussion in a future issue of the journal.

Proceedings journals rely entirely on contributions from the civil engineering profession (and allied disciplines). Information about how to submit your paper online is available at www.icevirtuallibrary.com/page/authors, where you will also find detailed author guidelines. 